\title{
Pulse Oximetry Effectivity For Measuring Oxygen Saturation In Hypovolemic Shock Patient Compared To Blood Gas Analysis At Rsup H. Adam Malik Medan
}

\author{
Jhonsen Indrawan' ${ }^{1}$, Yutu Solihat ${ }^{2}$, Dadik Wahyu Wijaya ${ }^{3}$, Akhyar H. Nasution ${ }^{4}$, Susi Sembiring ${ }^{5}$ \\ ${ }^{1}$ Resident of Anesthesiology and Intensive Therapy, Faculty of Medicine of Sumatera Utara University, Medan, Indonesia \\ ${ }^{2}$ Consultant in Anesthesiology and Intensive Therapy Department, RSUP H. Adam Malik and Faculty of Medicine of Sumatera Utara University, \\ Medan, Indonesia \\ ${ }^{3}$ Consultant in Anesthesiology and Intensive Therapy Department, RSUP H. Adam Malik and Faculty of Medicine of Sumatera Utara University, \\ Medan, Indonesia \\ ${ }^{4}$ Consultant in Anesthesiology and Intensive Therapy Department, RSUP H. Adam Malik and Faculty of Medicine of Sumatera Utara University, \\ Medan, Indonesia \\ ${ }^{5}$ Consultant in Anesthesiology and Intensive Therapy Department, RSUD dr. Pirngadi, Medan, Indonesia \\ Email : indrawan.jhonsen@gmail,com
}

DOI: 10.29322/IJSRP.10.08.2020.p10499

http://dx.doi.org/10.29322/IJSRP.10.08.2020.p10499

Abstract- Background : For patients with critical condition, healthcare professional need to asses actual body oxygenation as soon as possible. Until recently, the gold standard of this measurement is with blood gas analysis (BGA). Pulse oximetry is very useful by it's practicable and portable and been expected represent actual body oxygenation condition especially for nonBGA available centre.

Objective : To measure pulse oximetry's oxygen saturation accuracy for patients in shock condition in comparison to gold standard of BGA.

Method : This is an observational study and had collected cohort prospective data to acknowledge pulse oximetry accuracy for patients in shock condition based on Mean Arterial Pressure (MAP) $<65 \mathrm{mmHg}$ who admitted to emergency unit.

Result : This study include 39 subjects with mean age 53,36 years old, male composition $53,8 \%$ and female $46,2 \%$, dominated by MAP $>60 \mathrm{mHg}$ about $46,2 \%$, MAP 56-60 about $25,6 \%$, MAP $50-55$ about $17,9 \%$ and MAP $<50$ about $10,3 \%$. The mean result of peripheral oxygen saturation with pulse oximetry is $93,35 \pm 6,51 \%$, in comparison to arterial saturation of BGA about $98,21 \pm 3,50 \%$. The group of MAP $<50 \mathrm{mmHg}, 50-55 \mathrm{mmHg}, 56-60 \mathrm{mmHg}$ and $>60 \mathrm{mmHg}$ in shock condition patients ascertain that there is no difference between oxygen saturation based on pulse oximetry compared to BGA, by no statistical significance difference which $\mathrm{p}>0.05$.

Conclusion : Peripheral oxygen saturation based on pulse oximetry in patients with shock condition (MAP < 65mmHg) could represent actual arterial oxygen saturation by BGA as the gold standard.

Index Terms- Pulse oximetry, BGA, Oxygen saturation, mean arterial pressure (MAP), emergency, Peripheral oxygen saturation, Arterial oxygen saturation

\section{INTRODUCTION}

$\mathrm{C}$ ritical condition need oxygenation measurement as soon as possible. Oxygen partial pressure changing could cause hypoxia and induce vasoactive changing in the brain. In prevention of bad condition to the organ especially brain that could affect the prognosis, routine check of the oxygen saturation is a must. Until now, the mass usual measurement still remain in two, pulse oximetry and blood gas analysis, and the late one, is still the gold standard for this topic., ${ }^{1,2}$

Hypoxemia condition is hard detected, as ideal condition, clinically not significance until oxygen saturation below $80 \%$. Arterial oxygen is oxygen transfer from lung to cell that brought by haemoglobin molecule in red blood cell. Total amount of oxygen in blood include haemoglobin form bond with oxygen (9798\% of total) and oxygen dissolved in plasma (about 2\%). Haemoglobin level with oxygen in artery could measured with oxygen saturation $(\mathrm{SaO} 2)$ as the oxy-haemoglobin $(\mathrm{HbO} 2)$ compared to haemoglobin total in blood. In intensive care, an inadequate of oxygen to vital organ, put patient in high risk, we must to keep saturation $94 \%$ - $96 \%$ even with mechanical ventilation. Inaccuracy belief of SPO2 in critical patient is expected, because it's calibration for the healthy patient and could not applicable for critical patient. ${ }^{3}$

For shock condition, imbalance of oxygen transport and consumption could cause higher oxygen use. As critical condition, oxygen extraction with increase of oxygen delivery, and the consumption relate to it's delivery. Clinically venous saturation $5 \%$ decrease from normal point $70 \%$ indicate that significance decrease at oxygen delivery and or increase demand of oxygen. Venous saturation is also important that it's high level could show tissue inability for using oxygen.-6

Pulse oximetry is very useful because it is practicable and portable and could accompany medical health worker in any condition especially emergency. But for some condition, it is assumed that pulse oximetry could not give representative result 
for the actual body oxygenation condition such as shock and low blood pressure. Because it's practical and easy use that could give the best result and benefit for critical condition, we want to acknowledge it's accuracy for that condition we told first such as shock. This study especially discuss about using pulse oximetry for shock patients in emergency room for emergency situation, with mean arterial pressure (MAP) below $65 \mathrm{mmHg}$. $^{7,8}$

\section{METHOD}

This study is an descriptive analytic study with a cohort prospective design to acknowledge the accuracy of pulse oximetry in emergency room at Haji Adam Malik Hospital Medan. Total sampling is used to represent population which all subjects who come and meet the selection criteria are included in the study until the number of subjects is met. After obtaining approval from the Ethics Committee, Faculty of Medicine, University of North
Sumatra, based on inclusion and exclusion criteria 39 research samples were collected. All samples were admitted to emergency room with shock criteria, which MAP below $65 \mathrm{mmHg}$. At the same moment, we measured pulse oximetry at the index finger, blood pressure at the other arm, blood sample was taken from femoral artery. For normally test, we used software SPSS 24. Normal if $p>0.05$, and $p<0.05$ for not normal, we used one way Annova for normally distributed, and kruskal wallis for not normally distributed. Correlation was considered significant if the $\mathrm{p}$ value $<0.05$.

\section{RESULT}

This study was attended by 39 subjects who met the inclusion criteria. The characteristics of this study were displayed on table 4.1.

Table 4.1 Basic characteristics parameter of subject

\begin{tabular}{ll}
\hline Characteristics & $\mathbf{N}(\%)$ \\
\hline Age, years & $53,26 \pm 12,176$ \\
Gender, n(\%) & $21(53,8)$ \\
Male & $18(46,2)$ \\
Female & \\
Consciousness, n(\%) & $3(7,7)$ \\
Alert & $9(23,1)$ \\
Verbal & $26(66,7)$ \\
Pain & $1(2,6)$ \\
Unresponsive & $81,43 \pm 8,47$ \\
Systolic blood pressure, mmHg & $46,48 \pm 8,03$ \\
Diastolic blood pressure, mmHg & \\
MAP (Mean arterial pressure $)$ & $4(10,3)$ \\
$<50$ & $7(17,9)$ \\
50-55 & $10(25,6)$ \\
$56-60$ & $18(46,2)$ \\
$>60$ & $93,35 \pm 6,51$ \\
SpO2, \% & $98,21 \pm 3,50$ \\
SaO2, \% & $7,32 \pm 0,16$ \\
pH & $28,11 \pm 9,67$ \\
PCO2, mmHg & $148,23 \pm 40,06$ \\
PO2, mmHg & $17,83 \pm 10,26$ \\
HCO3, mEq/1 & $-8,71 \pm 10,54$ \\
BE &
\end{tabular}

From the analysis, using one way annova and kruskal wallis, we acknowledge that there is no significance difference statistically compared to MAP, for peripheral oxygen saturation by pulse oximetry, arterial oxygen saturation by $\mathrm{BGA}, \mathrm{pH}, \mathrm{PCO} 2, \mathrm{PO} 2, \mathrm{HCO} 3$ and Base Excess. The data is showed at table 4.2

Table 4.2 Oxygen saturation difference between pulse oximetry and BGA based on Mean arterial pressure (MAP) in shock patient

\begin{tabular}{llllll}
\hline & \multicolumn{2}{l}{ Mean Atrial Pressure $($ MAP $)$} & & Nilai p \\
\cline { 2 - 5 } & $\mathbf{5 0}$ & $\mathbf{5 0 - 5 5}$ & $\mathbf{5 6 - 6 0}$ & $\mathbf{6 0}$ & \\
\hline $\mathrm{SpO} 2$ & $98,5(91-99)$ & $88(82-99)$ & $93(68-99)$ & $96,5(82-99)$ & 0,096 \\
$\mathrm{SaO} 2$ & $99(97,6-100)$ & $99(79-100)$ & $99(93-100)$ & $99(96-100)$ & 0,871 \\
$\mathrm{pH}$ & $7,27(7,18-7,34)$ & $7,33(6,9-7,56)$ & $7,33(7,26-7,43)$ & $7,35(7,07-7,67)$ & 0,303 \\
$\mathrm{PCO} 2$ & $25,45 \pm 7,09$ & $25,28 \pm 8,44$ & $27,04 \pm 9,74$ & $30,41 \pm 10,66$ & 0,581
\end{tabular}




\begin{tabular}{llllll} 
PO2 & $136,5 \pm 44,32$ & $141,28 \pm 49,79$ & $154,36 \pm 44,79$ & $150,14 \pm 35,01$ & 0,854 \\
HCO3 & $12,35(8,5-12,9)$ & $15,3(4,3-28,4)$ & $12,35(9,7-34,5)$ & $18,9(5,60-50,0)$ & 0,313 \\
BE & $-15(-16-(-12,8))$ & $-9,8-(-26,9-4,6)$ & $-12,8-(-17,9-11)$ & $-8,4-(-20,3-24,6)$ & 0,465 \\
\hline
\end{tabular}

For acknowledge the comparison between $\mathrm{SpO} 2$ by pulse oximetry to $\mathrm{SaO} 2$ by $\mathrm{BGA}$ in measuring oxygen saturation, we used determination test to identify area under curve (AUC) from receiver operating characteristic (ROC) curve, that shown in table 4.3 to 4.6.

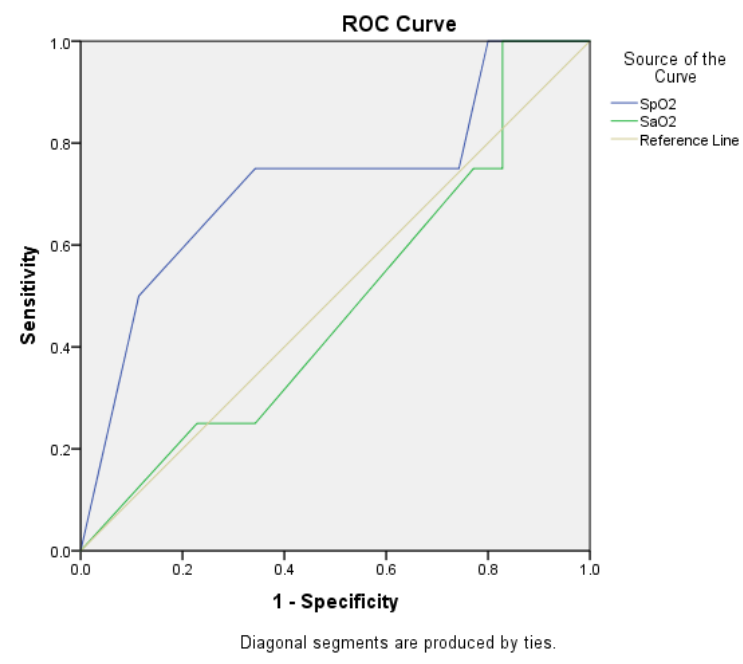

\begin{tabular}{|l|l|}
\hline 50-55 mmHg \\
\hline SpO2 & SaO2 \\
\hline Sen: $28,6 \%$ & Sen: $71,4 \%$ \\
Spes:6,2\% & Spes:12,5\% \\
AUC: 0,275 & AUC: 0,406 \\
Cut off: $82,5 \%$ & Cut off: $97,2 \%$ \\
p value: 0,065 & p value: 0,442 \\
\hline
\end{tabular}

Picture 4.1 The Comparison of $\mathrm{SpO} 2$ to $\mathrm{SaO} 2$ in measuring oxygen saturation for $\mathrm{MAP}<50$

Pulse oximetry could measure oxygen saturation until cut off $96.5 \%$ in shock patients with MAP $<50$ with $75.5 \%$ sensitivity and $62.9 \%$ specificity with fair relationship (AUC SpO2 0.721) compared to oxygen saturation by BGA in shock patients but there is no significance difference statistically as $\mathrm{p}>0.05$.

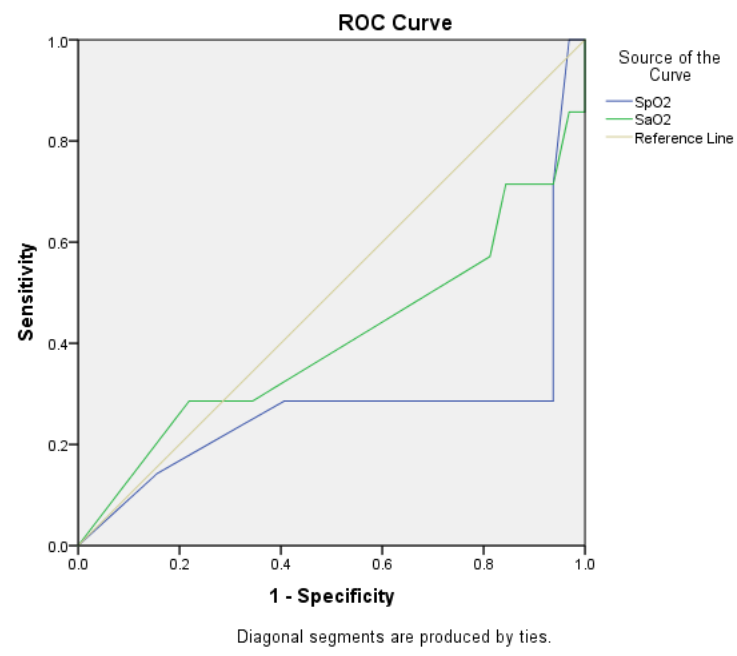

\begin{tabular}{|l|l|}
\hline \multicolumn{2}{|l|}{ MAP < 50 mmHg } \\
\hline SpO2 & SaO2 \\
\hline Sen: 75,5\% & Sen: 75,0\% \\
Spes:62,9\% & Spes:22,9\% \\
AUC: 0,721 & AUC: 0,486 \\
Cut off: 96,5\% & Cutoff:98,5\% \\
p value: 0,151 & p value: 0,926 \\
\hline
\end{tabular}

Picture 4.2 The Comparison of $\mathrm{SpO} 2$ to $\mathrm{SaO2}$ in measuring oxygen saturation for MAP 50-55.

Pulse oximetry could measure oxygen saturation until cut off $82.5 \%$ in shock patients with MAP 50-55 with $28.6 \%$ sensitivity and $6.1 \%$ specificity with no relationship (AUC SpO2 0.275) compared to oxygen saturation by BGA in shock patients but there is no significance difference statistically as $\mathrm{p}>0.05$. 


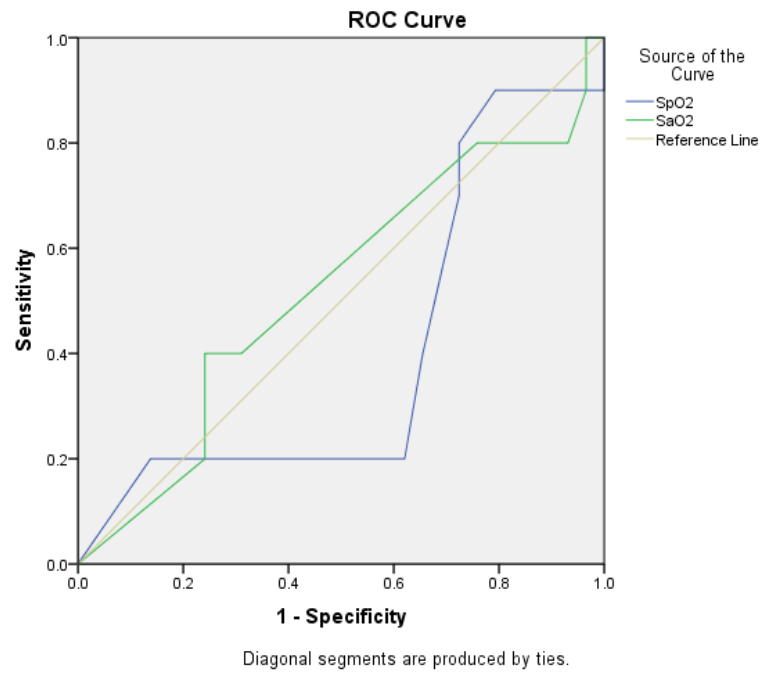

\begin{tabular}{|l|l|}
\hline 56-60 $\mathrm{mmHg}$ \\
\hline SpO2 & SaO2 \\
\hline Sen: $80 \%$ & Sen: $80 \%$ \\
Spes:27,6\% & Spes:24,1\% \\
AUC: 0,403 & AUC: 0,522 \\
Cut off: $91,5 \%$ & Cut off: $98,5 \%$ \\
p value: 0,368 & p value: $\mathbf{0 , 8 3 4}$ \\
\hline
\end{tabular}

Picture 4.3 The Comparison of $\mathrm{SpO} 2$ to $\mathrm{SaO} 2$ in measuring oxygen saturation for MAP 56-60.

Pulse oximetry could measure oxygen saturation until cut off $98.5 \%$ in shock patients with MAP 56-60 with $80 \%$ sensitivity and $24.1 \%$ specificity with poor relationship (AUC SpO2 0.522) compared to oxygen saturation by BGA in shock patients but there is no significance difference statistically as $\mathrm{p}>0.05$.

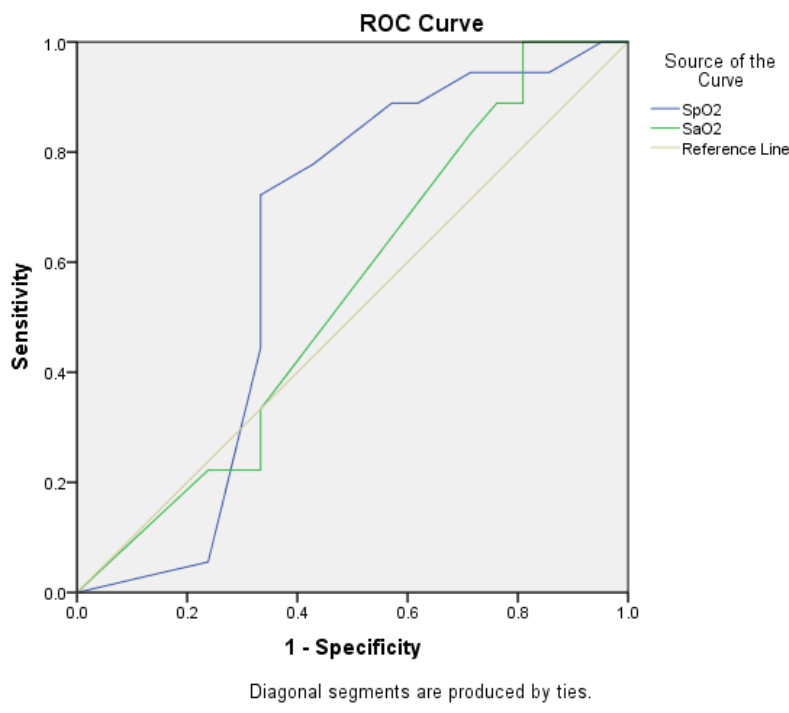

\begin{tabular}{|l|l|}
\hline \multicolumn{1}{|l|}{$60 \mathrm{mmHg}$} \\
\hline SpO2 & SaO2 \\
\hline Sen: $88,9 \%$ & Sen: $\mathbf{8 8 , 9 \%}$ \\
Spes:42,9\% & Spes:23,8\% \\
AUC: 0,626 & AUC: 0,544 \\
Cut off: $92,5 \%$ & Cut off: $97,8 \%$ \\
p value:0,181 & p value:0,642 \\
\hline
\end{tabular}

Picture 4.4 The Comparison of $\mathrm{SpO} 2$ to $\mathrm{SaO} 2$ in measuring oxygen saturation for $\mathrm{MAP}>60$.

Pulse oximetry could measure oxygen saturation until cut off $92.5 \%$ in shock patients with MAP> 60 with $88.9 \%$ sensitivity and $42.9 \%$ specificity with poor relationship (AUC SpO2 0.626) compared to oxygen saturation by BGA in shock patients but there is no significance difference statistically as $\mathrm{p}>0.05$.

\section{CONCLUSIONS}

Based on result and discussion, we conclude that:

1. Pulse oximetry could be used until MAP below $50 \mathrm{mmHg}$, where the result show no significance difference compared to oxygen saturation by BGA

2. Pulse oximetry could be used as basic for oxygen therapy so decrease mortality risk that caused by late action, in addition, as low as MAP, as much as possible become acidosis
3. Oxygen saturation is still related to microvascular blood flow, noticing also that the measuring could take time more as MAP get lower.

\section{REFERENCES}

[1] Proulx Jeffrey. Respiratory Monitoring: Arterial Blood Gas Analysis, Pulse Oximetry, and End-tidal Carbon Dioxide Analysis. Proulx. 2000: 14(4); 227 $230 \mathrm{p}$

[2] Yanda Srie, Lubis Munar, Yusroh Yoyoh. Comparison of oxygen saturation measured by pulse oximetry and arterial blood gas analysis in neonates. Pediatrica Indonesiana. 2004: 43(11); 211-214p 
[3] Razi Ebrahim, Akbari Hosein. A Comparison of Arterial Oxygen Saturation Measured Both by Pulse Oximeter and Arterial Blood Gas Analyzer in Hypoxemic and Non-Hypoxemic Pulmonary Diseases. Turkish Respiratory Journal. 2006; 7(2): 43-47

[4] Durlinger EMJ, Spoelstra de Man, Smit B, et al. Hyperoxia: At what level of $\mathrm{SpO} 2$ is a patient safe? A study in mechanically ventilated ICU patients. Elsevier. 2017; 39: 199-204p

[5] Wood Michael, Maslove David, Muscedere John, et al. Lowbrain tissue oxygenation contributes to the development of delirium in critically ill patients: A prospective observational study. Elsevier. 2017; 41: 289-295p

[6] Ortiz Esteban, Dunn F Jeff, Vasconez Jorge, et al. Review Article: Partial pressure of oxygen in the human body: a general review. Research Gate. 2019; 9(1):1-14p

[7] Higgins Chris. Oxygen saturation - better measured than calculated. Acutecaretesting. 2018: 1-6p

[8] Castro D, Keenaghan M. Arterial Blood Gas. Pubmed. 2019: 1-10p

\section{AUTHORS}

First Author - Jhonsen Indrawan, Resident of Anaesthesiology and Intensive Therapy, Faculty of Medicine, Universitas
Sumatera Utara, Medan, Indonesia, indrawan.jhonsen@gmail.com

Second Author - Yutu Solihat, Anaesthesiology and Intensive Therapy, RSUP H. Adam Malik and Faculty of Medicine, Universitas Sumatera Utara, Medan, Indonesia, Third Author - Dadik Wahyu Wijaya, Anaesthesiology and Intensive Therapy, , RSUP H. Adam Malik and Faculty of Medicine, Universitas Sumatera Utara,Medan, Indonesia Fourth Author - Akhyar H Nasution, Anaesthesiology and Intensive Therapy, , RSUP H. Adam Malik and Faculty of Medicine, Universitas Sumatera Utara,Medan, Indonesia, ahn14112019@gmail.com

Fifth Author - Susi Sembiring, Anaesthesiology and Intensive Therapy, RSUD dr. Pirngadi, Medan, Indonesia

Correspondence Author - Jhonsen Indrawan, indrawan.jhonsen@gmail.com, +62 85275357263 